CLINICAL STUDY

\title{
Screening for primary aldosteronism in hypertensive subjects: results from two German epidemiological studies
}

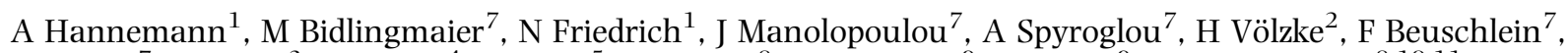 \\ J Seissler $^{7}$, R Rettig ${ }^{3}$, S B Felix ${ }^{4}$, R Biffar ${ }^{5}$, A Döring ${ }^{8}$, C Meisinger ${ }^{9}$, A Peters ${ }^{9}$, H E Wichmann ${ }^{8,10,11}$, M Nauck ${ }^{1}$, \\ $\mathrm{H}_{\text {Wallaschofski }}{ }^{1}$ and $\mathrm{M}$ Reincke ${ }^{7}$ \\ ${ }^{1}$ Institute of Clinical Chemistry and Laboratory Medicine, ${ }^{2}$ Institute for Community Medicine, ${ }^{3}$ Institute of Physiology. ${ }^{4}$ Clinic for Internal Medicine B, \\ ${ }^{5}$ Center of Oral Health and ${ }^{6}$ Institute of Pharmacology, Ernst-Moritz-Arndt-University Greifswald, Ferdinand-Sauerbruch-Straße, D-17475 Greifswald, \\ Germany, ${ }^{7}$ Medizinische Klinik und Poliklinik IV, Klinikum der Universität München, Munich, Germany, ${ }^{8}$ Institute of Epidemiology I and ${ }^{9}$ Institute of \\ Epidemiology II, Helmholtz Zentrum München, German Research Center for Environmental Health, Neuherberg, Germany, ${ }^{10}$ IBE-Chair of Epidemiology, \\ Ludwig-Maximilians-University, Munich, Germany and ${ }^{11}$ Klinikum Grosshadern, Munich, Germany
}

(Correspondence should be addressed to A Hannemann; Email: anke.hannemann@uni-greifswald.de)

\begin{abstract}
Objective: The prevalence of primary aldosteronism in unselected hypertensive patients is currently unknown. We investigated the frequency of positive screening results for primary aldosteronism based on the aldosterone-to-renin ratio (ARR) in hypertensive subjects aged 30-79 years from two German epidemiological studies. We further examined the frequency of positive screening results in subjects with resistant hypertension or stage III hypertension and assessed possible disparities between untreated and treated hypertensive subjects.

Methods: Data were obtained from the first follow-ups of the population-based Study of Health in Pomerania (SHIP; $n=1392$ ) and the Cooperative Health Research in the Region of Augsburg (KORA; $n=1052$ ). Study-specific reference ranges for plasma aldosterone concentration (PAC), plasma renin concentration (PRC) and the ARR were applied. Confirmation tests for primary aldosteronism were not performed in these epidemiological studies. Three definitions for a positive screening for primary aldosteronism were applied: A) increased ARR; B) increased ARR and decreased PRC; and C) increased ARR and increased PAC and decreased PRC.

Results: The frequency of positive screening results was 7.0, 3.8 and $0.2 \%$ according to definitions A-C respectively. In the subgroups of subjects with resistant hypertension $(11.9,5.5$ and $0.9 \%)$ or stage III hypertension $(18.3,14.0$ and $1.1 \%)$, these frequencies were markedly higher than those in the general hypertensive population. There was no difference in the frequency of positive screening results between the treated and untreated hypertensive subjects.

Conclusions: A maximum of $7.0 \%$ of the hypertensive population in Germany shows a positive screening result for primary aldosteronism. Thus, primary aldosteronism may be less frequent than previously expected based on data from referred hypertensive patients.
\end{abstract}

European Journal of Endocrinology 167 7-15

\section{Introduction}

Arterial hypertension is an important predictor of cardiovascular morbidity and mortality (1, 2, 3). Patients with primary aldosteronism experience severe hypertension that is caused by excessive aldosterone secretion (4). Moreover, patients with primary aldosteronism exhibit higher rates of cardiovascular events and end-organ damage than patients with essential hypertension $(5,6)$. In screening for primary aldosteronism, the aldosterone-to-renin ratio (ARR) is widely accepted (7), as it indicates autonomous aldosterone production. While increased ARRs are a hallmark of primary aldosteronism, they also occur in hypertensive subjects with decreased renin in combination with normal or even decreased aldosterone levels (8). The underlying causes of low-renin hypertension and primary aldosteronism are manifold and can be acquired or genetically determined (9).

The Endocrine Society recommends screening for primary aldosteronism in patient groups with a high prevalence (4). The prevalence of primary aldosteronism increases with the severity of hypertension and varies depending on the population under investigation (10). In a recent meta-analysis, Jansen et al. (10) 
determined a mean prevalence of primary aldosteronism of $4.3 \%$ in hypertensive primary care patients and $9.0 \%$ in referred hypertensive patients.

The impact of ARR-altering antihypertensive medication in the screening for primary aldosteronism is controversially discussed $(11,12,13,14)$. A recent study (11) investigated whether washout or replacement of medication, as recommended by the Endocrine Society (4), is possible and necessary in individual patients. The results of this study (11) suggest that even under regular antihypertensive therapy, the ARR has a high sensitivity in the detection of primary aldosteronism.

While previous studies investigated the prevalence of primary aldosteronism in selected hypertensive patients in primary care $(15,16,17,18)$ or referred hypertensive patients in clinical centres $(19,20,21,22)$, the frequency of primary aldosteronism in unselected hypertensive subjects is currently unknown. Based on the ARR, plasma aldosterone concentration (PAC) and plasma renin concentration (PRC), we investigated the frequency of positive screening results for primary aldosteronism in hypertensive subjects from the general population in Germany. Data were obtained from the first follow-ups of two population-based studies: the Study of Health in Pomerania (SHIP) and the Cooperative Health Research in the Region of Augsburg (KORA). We applied three definitions of a positive screening result, which vary according to the degree of sensitivity and specificity for primary aldosteronism: A) increased ARR; B) increased ARR and decreased PRC; and C) increased ARR with increased PAC and decreased PRC. We further assessed the frequency of positive screening results in two subgroups of study participants: patients with resistant hypertension and those with stage III hypertension. Finally, we investigated the possible disparities in the distribution of PAC, PRC and ARR and in the frequency of positive screening results between untreated and treated hypertensive study participants.

\section{Materials and methods}

\section{The Study of Health in Pomerania}

SHIP is a population-based health survey conducted in northeast Germany between 1997 and 2001. From the target population consisting of all German residents of the region, a two-stage cluster sample of 7008 subjects aged 20-79 years was obtained. The study design and sampling methods were previously described (23). Of all the 4308 participants of the SHIP-0 baseline examination, 3300 also participated in the first 5-year follow-up, designated as SHIP-1. PAC and PRC were measured in SHIP-1 but not in SHIP-0; therefore, we restricted all analyses to SHIP-1.

\section{Cooperative Health Research in the Region of Augsburg}

KORA S4 is a population-based health survey conducted in south Germany between 1999 and 2001. From the target population consisting of all German residents of the region, a two-stage cluster sample of 6640 subjects aged 25-74 years was obtained. The study design and sampling methods were previously described (24). Of all the 4261 participants of the KORA S4 baseline study, 3080 subjects aged $31-82$ years also participated in the 7-year follow-up KORA F4 study. PAC and PRC were measured in KORA F4 but not in KORA S4; therefore, we restricted all analyses to KORA F4.

\section{Study population}

Our study population comprised 1630 hypertensive SHIP-1 and 1174 hypertensive KORA F4 participants. Among those, we excluded all subjects with missing PAC or PRC (SHIP-1: $n=52$; KORA F4: $n=12$ ), pregnant women (SHIP-1: $n=2$; KORA F4: $n=0$ ), subjects with renal insufficiency defined as creatinine clearance $<50 \mathrm{ml} / \mathrm{min}$ or subjects with missing data on renal function (SHIP-1: $n=102$; KORA F4: $n=79$ ) and subjects outside the age range of 30-79 years (SHIP-1: $n=82$; KORA F4: $n=31$ ). Some subjects were excluded for multiple reasons. This resulted in a study population of 2444 subjects, consisting of 1392 SHIP-1 and 1052 KORA F4 participants.

The investigations in SHIP and KORA were conducted in accordance with the Declaration of Helsinki, and written informed consent was obtained from all participants. The survey and study methods of both studies were approved by institutional review boards (SHIP: ethics committee of the University of Greifswald; KORA: ethics committee of the Bavarian Chamber of Physicians, Munich).

\section{Interview and physical examination}

All SHIP-1 and KORA F4 participants underwent a standardised medical examination, including blood sampling and measurements of systolic and diastolic blood pressure. In both studies, information on medical history was obtained by trained and certified staff during a computer-assisted personal interview using identical methods.

Techniques of blood pressure measurement were similar in SHIP-1 and KORA F4 as previously reported (25). After a rest period of at least $5 \mathrm{~min}$, systolic and diastolic blood pressures were measured three times on the right arm of the seated participant using a digital blood pressure monitor (HEM-705CP; OMRON Corporation, Tokyo, Japan). For statistical analyses, the mean of the second and third measurements was used. Subjects with systolic or diastolic blood pressures $\geq 140$ or $\geq 90 \mathrm{mmHg}$ respectively, or self-reported 
history of hypertension and intake of antihypertensive medication were considered to be hypertensive. The SHIP-1 and KORA F4 participants were asked to bring along all drugs taken in the 7 days preceding the examination. The drugs were categorised according to the anatomical therapeutic chemical classification system. In both studies, drugs were assigned as 'antihypertensive medication' if the compounds were classified as antihypertensively effective based on the guidelines of the German Hypertension Society (SHIP-1: 18th edition, KORA F4: 19th edition). Resistant hypertension was defined as systolic or diastolic blood pressure $\geq 140$ or $\geq 90 \mathrm{mmHg}$ respectively, despite treatment with three or more antihypertensive agents, one of which had to be a diuretic; in addition, resistant hypertension was defined as a blood pressure $<140 / 90 \mathrm{mmHg}$ with four or more antihypertensive agents, one of which had to be a diuretic (26). Stage III hypertension was defined as systolic or diastolic blood pressures $\geq 180$ or $\geq 110 \mathrm{mmHg}$ (27) respectively, in subjects taking antihypertensive medication.

Blood samples in SHIP-1 and KORA F4 were taken, while subjects were on regular salt diet and under regular medication. In SHIP-1, blood was sampled between 0800 and $1930 \mathrm{~h}$ from non-fasting subjects in the supine position. In KORA F4, blood was sampled in the morning between 0730 and $1030 \mathrm{~h}$ from fasting (at least $10 \mathrm{~h}$ ), seated subjects. As shown in a previous study (28), blood sampling time and fasting status did not significantly affect PAC, PRC or ARR.

\section{Laboratory measurements}

Serum potassium was measured with indirect potentiometry with ion-selective electrodes (SHIP-1 and KORA F4: QuikLYTE; Dade Behring, Eschborn, Germany). Hypokalaemia was defined as serum potassium concentrations $<3.5 \mathrm{mmol} / \mathrm{l}$.

In SHIP-1 and KORA F4, PAC and PRC were measured in EDTA plasma samples in centralised laboratories (SHIP-1: Institute of Clinical Chemistry and Laboratory Medicine, University Medicine Greifswald, Greifswald, Germany; KORA F4: Medizinische Klinik und Poliklinik IV, Klinikum der Universität München, Munich, Germany). Following the blood sampling, the SHIP-1 EDTA plasma samples were stored on ice and transported within $15 \mathrm{~min}$ to the Institute of Clinical Chemistry and Laboratory Medicine. After centrifugation, all samples were stored at $-80{ }^{\circ} \mathrm{C}$. PAC and PRC were measured using radioimmunometric procedures (PAC, Coat-ACount Aldosterone; Siemens Healthcare Diagnostics, Eschborn, Germany; PRC, Renin III generation; Cisbio Bioassay, Bagnols-sur-Cèze Cedex, France) as previously reported (28). The inter- and intra-assay coefficients of variation (CV) of the PAC assay were 15.7 and $5.4 \%$ at low concentrations and 3.8 and $2.3 \%$ at high concentrations respectively. The inter- and intra-assay $\mathrm{CV}$ of the PRC assay were 5.0 and $3.6 \%$ at low concentrations and
4.0 and $0.9 \%$ at high concentrations respectively. The PAC measured in SHIP-1 corresponds well with data from previous reports using the same assay $(29,30,31)$. In KORA F4, the EDTA plasma samples were not cooled during the $30 \mathrm{~min}$ between blood sampling and centrifugation. After centrifugation, all samples were stored at $-80^{\circ} \mathrm{C}$. PAC was measured after extraction using an immunofluorescence in-house assay as reported elsewhere (32). The inter- and intra-assay CV were 15.2 and $7.3 \%$ at low concentrations as well as 8.0 and $4.4 \%$ at high concentrations respectively. PRC was measured using an automated chemiluminescence immunoassay (LIAISON Direct Renin, DiaSorin, Dietzenbach, Germany) (33). The intra- and inter-assay CV were below 5.6 and $12.2 \%$ respectively.

Previous studies $(8,34)$ demonstrated that in low renin states, plasma renin activity (PRA) assays provide more sensitive results than PRC assays. However, PRA assays are far more labour intensive than PRC assays, and their use in clinical routine decreased substantially over the past years. Thus, PRC instead of PRA was measured in SHIP-1 and KORA F4 because it better reflects the current laboratory standards.

\section{Definition of decreased, normal and increased PAC, PRC and ARR}

The differences in blood sampling conditions and laboratory measurements between SHIP-1 and KORA F4 required the use of study-specific cut-offs to differentiate among decreased, normal and increased levels of PAC, PRC and ARR. Therefore, we established study-specific reference ranges for PAC, PRC and ARR before the present analyses (28). Reference range calculations were performed similarly in SHIP-1 and KORA F4. In short, reference populations were selected by excluding all participants with missing data on PAC or PRC, participants with hypokalaemia, renal insufficiency and all pregnant women. Further exclusion criteria were: systolic blood pressure $\geq 140 \mathrm{mmHg}$ or diastolic blood pressure $\geq 90 \mathrm{mmHg}$; intake of antihypertensive medication including antiadrenergic agents, diuretics, calcium channel blockers, ACE inhibitors or angiotensin II receptor antagonists; and age above 74 years (SHIP-1) or 80 years (KORA F4). The reference ranges represent the weighted 2.5 th and 97.5th sex-specific percentiles of the PAC, PRC and ARR distributions for the two age groups, $<55$ and $\geq 55$ years (Table 1). Weights accounted for dropout between the baseline and follow-up examinations based on sociodemographic and health-related variables.

\section{Positive screening for primary aldosteronism}

A positive screening result for primary aldosteronism was defined according to three definitions: A) increased ARR; B) increased ARR and decreased PRC; and C) increased ARR with increased PAC and decreased 
Table 1 Age- and sex-specific reference ranges for PAC, PRC and ARR in SHIP-1 and KORA F4. To convert PAC in ng/dl, divide by 10; to convert PAC to pmol/l, multiply by 2.775 ; to convert PRC to pmol/l, multiply by 0.0237 .

\begin{tabular}{|c|c|c|c|c|c|}
\hline \multirow[b]{2}{*}{ Variable } & \multirow{2}{*}{$\begin{array}{l}\text { Age group } \\
\text { (years) }\end{array}$} & \multicolumn{2}{|c|}{ SHIP-1 ${ }^{a}$} & \multicolumn{2}{|c|}{ KORA F4 } \\
\hline & & Males & Females & Males & Females \\
\hline \multirow[t]{2}{*}{ PAC (ng/l) } & $<55$ & $12.0-140.0$ & $5.0-139.0$ & $8.0-108.0$ & $8.0-200.0$ \\
\hline & $\geq 55$ & $6.0-113.0$ & $5.0-130.0$ & $8.0-136.0$ & $8.0-136.0$ \\
\hline \multirow{2}{*}{ PRC (ng/l) } & $<55$ & $3.5-26.9$ & $2.6-21.1$ & $1.6-25.8$ & $1.1-23.5$ \\
\hline & $\geq 55$ & $2.3-22.7$ & $1.7-23.5$ & $1.5-25.5$ & $0.8-18.8$ \\
\hline \multirow[t]{2}{*}{ ARR } & $<55$ & $1.4-14.2$ & $0.9-20.3$ & $0.9-21.5$ & $1.4-43.8$ \\
\hline & $\geq 55$ & $0.9-22.4$ & $0.7-25.5$ & $1.3-25.5$ & $1.5-54.9$ \\
\hline
\end{tabular}

PAC, plasma aldosterone concentration; PRC, plasma renin concentration; ARR, aldosterone-to-renin ratio.

${ }^{a}$ As published by Hannemann et al. (28).

PRC. Definition C describes the typical profile observed in primary aldosteronism: an increased ARR resulting from autonomous aldosterone release and suppressed renin secretion. We therefore assume that a high proportion of subjects who qualify for definition C may suffer from primary aldosteronism, whereas this condition may be less frequent in subjects that fulfil the criteria of definitions A or B only. While the number of false-negative screening results is lower under the definitions $\mathrm{A}$ and $\mathrm{B}$, these definitions are less specific for primary aldosteronism and thus provide a higher number of false-positive results than definition $C$. Unfortunately, confirmatory tests for primary aldosteronism could not be performed due to the populationbased study design.

\section{Statistical analyses}

Due to the skewed distributions of PAC, PRC and ARR values, we report median values. Dichotomous variables

Table 2 Characteristics of the study population. Continuous variables are given as mean (1 S.D.); PAC, PRC and ARR are given as median (1st-3rd quartile); and dichotomous variables are given as $\%$. Group comparisons were performed using Kruskal-Wallis tests for continuous variables, $\chi^{2}$ tests for categorical variables. Due to differences in blood sampling and laboratory methods, we present median values for PAC, PRC and ARR separately for SHIP-1 and KORA F4. To convert PAC in ng/dl, divide by 10 ; to convert PAC in pmol//, multiply by 2.775 . To convert PRC in pmol/l, multiply by 0.0237 .

\begin{tabular}{|c|c|c|c|}
\hline Characteristics & $\begin{array}{l}\text { Untreated } \\
\text { subjects } \\
(n=837)\end{array}$ & $\begin{array}{l}\text { Treated } \\
\text { subjects } \\
(n=1607)\end{array}$ & $\boldsymbol{P}$ \\
\hline Male/female (\%) & $63.2 / 36.8$ & $52.4 / 47.6$ & $<0.001$ \\
\hline Age (years) & $54.6(11.9)$ & $63.1(10.3)$ & $<0.001$ \\
\hline $\mathrm{BMI}\left(\mathrm{kg} / \mathrm{m}^{2}\right)$ & $28.8(4.7)$ & $30.3(5.0)$ & $<0.001$ \\
\hline Smokers (\%) & 23.3 & 12.5 & $<0.001$ \\
\hline Systolic BP (mmHg) & $148.5(13.3)$ & $136.5(20.0)$ & $<0.001$ \\
\hline Diastolic BP $(\mathrm{mmHg})$ & $91.1(8.6)$ & $80.5(11.5)$ & $<0.001$ \\
\hline Potassium (mmol/l) & $4.3(0.3)$ & $4.2(0.3)$ & $<0.001$ \\
\hline Hypokalaemia (\%) & 0.7 & 1.6 & 0.079 \\
\hline \multicolumn{4}{|l|}{$\begin{array}{l}\text { Treatment with } \\
\text { antihypertensive } \\
\text { medication }\end{array}$} \\
\hline$\beta$-Blockers (\%) & - & 59.7 & - \\
\hline ACE inhibitors (\%) & - & 47.7 & - \\
\hline Diuretics (\%) & - & 34.9 & - \\
\hline $\begin{array}{l}\text { Calcium channel } \\
\text { blockers (\%) }\end{array}$ & - & 24.7 & - \\
\hline $\begin{array}{l}\text { Angiotensin II receptor } \\
\text { antagonists (\%) }\end{array}$ & - & 21.8 & - \\
\hline $\begin{array}{l}\text { Antiadrenergic agents } \\
\text { (\%) (excluding } \\
\beta \text {-blockers) }\end{array}$ & - & 4.2 & - \\
\hline PAC (SHIP-1) (ng/l) & $46.0(29.0-69.0)$ & $41.0(25.0-64.0)$ & 0.012 \\
\hline PAC (KORA F4) (ng/l) & $40.0(26.2-54.0)$ & $38.0(26.0-58.0)$ & 0.846 \\
\hline PRC (SHIP-1) (ng/l) & $7.3(4.6-11.2)$ & $9.4(4.8-22.8)$ & $<0.001$ \\
\hline PRC (KORA F4) (ng/l) & $6.4(3.3-9.8)$ & $8.6(3.4-22.2)$ & $<0.001$ \\
\hline ARR (SHIP-1) & $6.3(3.4-10.5)$ & $4.1(1.6-9.0)$ & $<0.001$ \\
\hline ARR (KORA F4) & $6.4(3.5-10.8)$ & $4.4(1.5-11.7)$ & $<0.001$ \\
\hline
\end{tabular}

$\mathrm{BMI}$, body mass index; $\mathrm{BP}$, blood pressure; $\mathrm{ACE}$, angiotensin-converting enzyme; PAC, plasma aldosterone concentration; PRC, plasma renin concentration; ARR, aldosterone-to-renin ratio. 


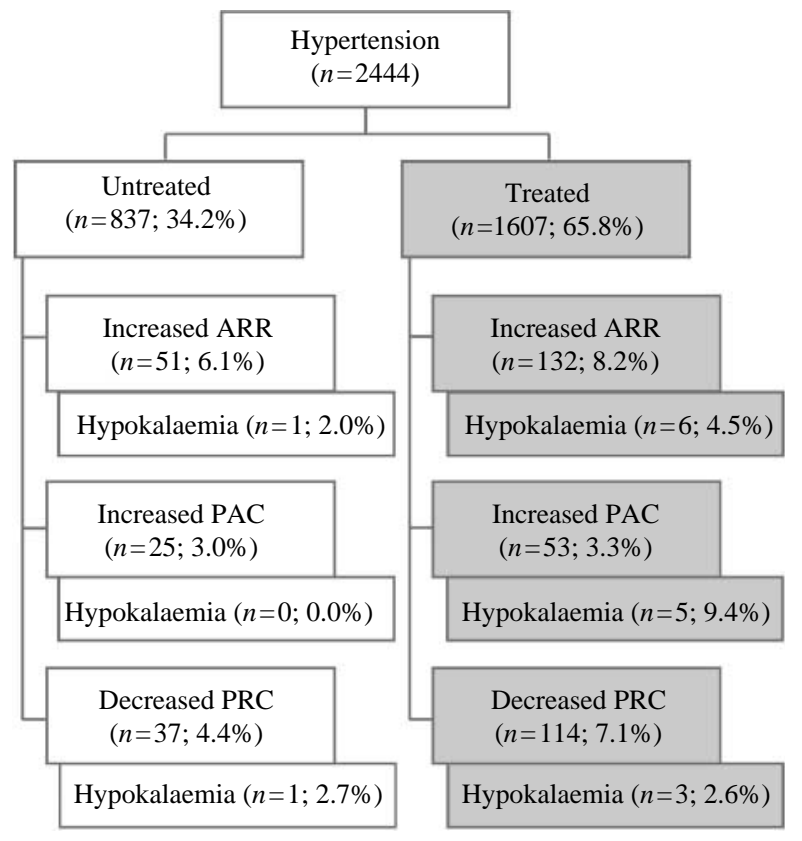

Figure 1 Classification of untreated and treated hypertensive subjects according to ARR, PAC and PRC.

are presented as percentages. Group comparisons were performed using Kruskal-Wallis tests for continuous variables and $\chi^{2}$ tests for categorical variables. $P$ values $<0.05$ were considered statistically significant. All data were weighted to reflect the age and sex structure of the German population in 2008. All statistical analyses were performed using SAS 9.1 (SAS Institute, Inc., Cary, $\mathrm{NC}, \mathrm{USA}$ ).

\section{Results}

Among the 2444 hypertensive subjects in our study population, the majority $(n=1607 ; 65.8 \%)$ were treated with antihypertensive medication. The 837 (34.2\%) untreated hypertensive subjects were on average 8.5 years younger, had lower BMI, higher systolic and diastolic blood pressures and were more often smokers than the treated hypertensive subjects (Table 2). Less than $2.0 \%$ of our study population was hypokalaemic. Of the 183 subjects with increased ARR, $3.8 \%(2.0 \%$ untreated and $4.5 \%$ treated) were hypokalaemic (Fig. 1). Five (all of them treated) of 78 subjects with increased PAC as well as nine (one untreated and eight treated) of 151 subjects with decreased PRC were hypokalaemic.

According to definitions $\mathrm{A}, \mathrm{B}$ and $\mathrm{C}, 7.0,3.8$ and $0.2 \%$ of the study population had a positive screening result after standardisation to the age and sex structure of the German population in 2008 (Table 3). In our study population, we detected 178 participants with resistant hypertension. Sixteen $(9.0 \%)$ fulfilled the criteria of definition A, eight (4.5\%) fulfilled the criteria of definition B and two (1.1\%) fulfilled the criteria of definition $C$. We detected an additional 93 participants with stage III hypertension. Seventeen (18.3\%) fulfilled the criteria of definition A, thirteen $(14.0 \%)$ fulfilled the criteria of definition $\mathrm{B}$ and one $(1.1 \%)$ fulfilled the criteria of definition $\mathrm{C}$.

According to definitions $\mathrm{A}, \mathrm{B}$ and $\mathrm{C}$, the frequencies of positive screening results were $5.9,2.6$ and $0.0 \%$ in untreated hypertensive subjects and 8.5, 4.9 and $0.5 \%$ in treated hypertensive subjects respectively (Table 3). Among the 1607 treated hypertensive subjects, 956 (59.5\%) used a combination of more than one antihypertensive agent. The average number of antihypertensive drugs per individual was 1.9 (one s.D. 1.0).

\section{Discussion}

Our findings indicate that between 0.2 and $7.0 \%$ of the hypertensive SHIP-1 and KORA F4 study population fulfilled the criteria for a positive screening result for primary aldosteronism, according to the three aforementioned definitions. In the subgroups of patients with resistant hypertension and stage III hypertension, these proportions were markedly higher.

Primary aldosteronism is one of the major forms of secondary hypertension $(35,36)$. The Endocrine Society recommends screening for primary aldosteronism in patient groups with a high pre-test probability, including patients with severe or resistant hypertension, incidentaloma, hypokalaemia or with early onset of hypertension (4). In contrast, the Japan Endocrine Society recommends the investigation of primary aldosteronism in all hypertensive patients (37). We found that $7.0 \%$ of the examined hypertensive subjects

Table 3 Standardised frequencies of positive screening results for primary aldosteronism in hypertensive subjects. Frequencies were weighted to reflect the age and sex structure of the German population in 2008.

\begin{tabular}{lc}
\hline $\begin{array}{l}\text { Definition of positive screening } \\
\text { results for primary aldosteronism }\end{array}$ & $\begin{array}{c}\text { Standardised } \\
\text { frequency }(\%) \\
(95 \% \mathrm{Cl})\end{array}$ \\
\hline Definition A (increased ARR) & \\
All hypertensives & $7.0(6.0-8.0)$ \\
$\quad$ Untreated & $5.9(4.3-7.5)$ \\
Treated & $8.5(7.1-9.9)$ \\
Definition B (increased ARR and & \\
$\quad$ decreased PRC) & $3.8(3.0-4.5)$ \\
All hypertensives & $2.6(1.5-3.7)$ \\
Untreated & $4.9(3.8-6.0)$ \\
$\quad$ Treated & \\
Definition C (increased ARR and increased & \\
$\quad$ PAC and decreased PRC) & $0.2(0.0-0.4)$ \\
All hypertensives & $0.0(-)$ \\
Untreated & $0.5(0.2-0.8)$ \\
$\quad$ Treated &
\end{tabular}

$\mathrm{Cl}$, confidence interval; PAC, plasma aldosterone concentration; PRC, plasma renin concentration; ARR, aldosterone-to-renin ratio. 
had an increased ARR after standardisation to the age and sex structure of the German population in 2008. An increased ARR with suppressed PRC secretion, a key characteristic of primary aldosteronism, was identified in $3.8 \%$ of our hypertensive study population. The typical laboratory constellation of primary aldosteronism, an increased ARR in combination with increased PAC and decreased PRC, was exhibited by only $0.2 \%$ of the hypertensive study population. As there were no confirmatory tests in SHIP-1 or KORA F4, exact estimates for the frequency of primary aldosteronism cannot be provided by this study. However, we assume that the frequency of primary aldosteronism in our hypertensive population lies within the range of $0.2-$ $7.0 \%$. With up to $7.0 \%$ of the hypertensive cohort giving a positive result, our findings support the recommendations of the Endocrine Society to screen for primary aldosteronism in subgroups of patients with a high pre-test probability.

Previous studies investigating the prevalence of primary aldosteronism focused on hypertensive subjects, either in primary care $(15,17,18)$ or in hypertension referral centres $(19,20,21,22)$. In a recent meta-analysis (10), the prevalence of primary aldosteronism ranged from 0.7 to $13.0 \%$ (mean $4.3 \%$ ) in the compiled studies including primary care patients and from 5.9 to $24.0 \%$ (mean $9.0 \%$ ) in the studies including referred patients. Our estimates obtained in hypertensive subjects from the general population correspond to the low to medium range of estimates for the prevalence of primary aldosteronism in primary care patients. Compared with the mean prevalence of primary aldosteronism observed in referred patients, the prevalence of positive screening results for primary aldosteronism in our hypertensive study population was low. In the ongoing debate regarding the prevalence of primary aldosteronism $(38,39)$, our results indicate a lower prevalence in hypertensive subjects from the general population than in hypertensive subjects referred to specialised centres.

Previous studies $(18,40)$ also demonstrated that more severe forms of hypertension, e.g. resistant hypertension or stage III hypertension, are associated with a high prevalence of primary aldosteronism. In resistant hypertension, primary aldosteronism was diagnosed in $20.0 \%$ (40); among patients with stage III hypertension, primary aldosteronism was diagnosed in $13.2 \%(18)$. Our results are consistent with these studies $(18,40)$. The frequencies of positive screening results were markedly higher in the subgroups of study participants with resistant hypertension or stage III hypertension than in the entire study population.

Before our study, Olivieri et al. (41) determined the prevalence of increased ARRs in a sample of randomly selected, representative, hypertensive subjects from the Bussolengo Health District in Northern Italy. Among 287 examined hypertensive subjects, $32.4 \%$ presented an increased ARR (PAC to active renin concentration).
The cut-off for an increased ARR was determined to be equivalent to 50 when PRA is measured. In another study, Newton-Cheh et al. (42) analysed data from the sixth examination cycle of the community-based Framingham Offspring Cohort. The authors found that $7.9 \%$ of 215 untreated hypertensive men and $23.1 \%$ of 229 untreated hypertensive women had increased ARR (serum aldosterone concentration to PRC). The cut-off for an increased ARR was adopted from a previous study. In this study, a different approach was used to define increased ARR levels, the application of study-specific reference ranges. To the best of our knowledge, this approach has not been used earlier. The different frequencies of increased ARRs obtained in this study and the studies by Olivieri et al. (41) and Newton-Cheh et al. (42) may result from these methodological differences.

The intake of certain antihypertensive agents complicates the evaluation of increased ARR levels due to the effects on PAC and PRC (4). In our study, 311 hypertensive subjects were treated with antiadrenergic agents, which increase ARR and may produce falsepositive screening results. An increased ARR was detected in $46(14.8 \%)$ of these subjects. Another 340 hypertensive subjects were treated with diuretics, calcium channel blockers, ACE inhibitors or angiotensin II receptor antagonists, which decrease ARR and may produce false-negative screening results. An increased ARR was detected in seven $(2.1 \%)$ of these subjects. Finally, 956 hypertensive subjects were treated with a combination of more than one antihypertensive agent. An increased ARR was detected in 79 (8.3\%) of these subjects. Unfortunately, washout or change of antihypertensive medication was not possible in SHIP or KORA. Moreover, confirmation tests for primary aldosteronism were not performed; therefore, we cannot assess the proportions of true- or false-positive and trueor false-negative screening results in the treated hypertensive subjects. A recent study (11) compared the mean PAC, PRC and ARR in 25 patients with essential hypertension and in 25 patients with primary aldosteronism. Blood sampling was performed while subjects were taking their regular antihypertensive medication and again after a discontinuation of medication or after a change to drugs with minimal influence on ARR. This study (11) found that antihypertensive medication exerts stronger effects on PAC, PRC and ARR in essential hypertension than in primary aldosteronism. In patients with essential hypertension, the change of medication led to a reduction of false-positive screening results from 11 of 25 patients at baseline to five of 25 patients after substitution or discontinuation of the regular medication. The majority ( 24 of 25 ) of patients with primary aldosteronism presented an increased ARR even while taking regular antihypertensive medication. When the ARR was interpreted in combination with information on PAC and potassium, all patients with primary 
aldosteronism were detected. Moreover, the aforementioned study (11) demonstrated that a change or discontinuation of antihypertensive medication may cause severe side effects. We therefore have reasonable justification to assume that although two-thirds of our study population was on antihypertensive treatment, the sensitivity of our screening results is high.

In our study population, it was impossible to modify antihypertensive medication. However, in clinical practice, screening for primary aldosteronism should be performed after withdrawal or change of antihypertensive medication to drugs with minimal effects on the ARR (4).

Our study has several strengths as well as limitations. The study is strengthened by the large sample size taken from two distinct German regions. In addition, all examinations and laboratory measurements were performed by certified examiners following standardised protocols, assuring excellent quality of data. As the conditions of blood sampling and laboratory methods differed, we applied study-specific reference ranges for PAC, PRC and ARR and were thus able to provide a joint result for both SHIP-1 and KORA F4. Limitations of our study arise from the intake of and unknown compliance with prescribed antihypertensive medication, the singleoccasion blood pressure measurement, the lack of confirmatory testing, the use of follow-up data and the random sodium intake of our participants. Treated hypertensive subjects may present false-positive or falsenegative screening results for primary aldosteronism as various classes of antihypertensive medication alter PAC, PRC and ARR (4). Moreover, data on compliance with antihypertensive drug treatment were not collected in either SHIP-1 or KORA F4. This may have led us to overestimate the proportion of subjects with active antihypertensive drug treatment as well as resistant hypertension, as compliance is a general problem in antihypertensive treatment (26). For the definition of hypertension, repeated measurements of blood pressure on two or more occasions are recommended. A re-examination of the blood pressure on a second occasion was not possible due to the study design. However, to avoid a white-coat hypertension effect, three subsequent blood pressure measurements were performed, of which the mean of the second and third was used for the statistical analysis. Unfortunately, it was not possible to perform confirmatory tests for primary aldosteronism in SHIP-1 or KORA F4 due to the epidemiological study design. We therefore presented a range of three estimates, within which the frequency of primary aldosteronism presumably lies, but the exact prevalence of primary aldosteronism in our study population remains unknown. Furthermore, while the baseline examinations of SHIP-0 and KORA S4 provide population-based results, the analysed data from the follow-up studies deviate slightly from representativity. Finally, we cannot exclude that differences in salt intake among the age, sex or regional subgroups of the study population biased our results by influencing ARR (43). In addition to these limitations, all our data were obtained from Caucasian subjects, thus the transferability of our results to other ethnicities may be limited.

Taken together, our results suggest that in the hypertensive German population, positive screening results for primary aldosteronism are found in a maximum of $7.0 \%$ of subjects. Thus, primary aldosteronism is less frequent among our hypertensive subjects from the general population than in previous studies among referred hypertensive patients. Our data thereby support the recommendations of the Endocrine Society to restrict screening for primary aldosteronism to subgroups of hypertensive patients with high risk for primary aldosteronism.

\section{Declaration of interest}

The authors declare that there is no conflict of interest that could be perceived as prejudicing the impartiality of the research reported.

\section{Funding}

The SHIP research platform is part of the Community Medicine Research net (CMR) of the University Medicine Greifswald, Germany, which is funded by the Federal Ministry of Education and Research, the Ministry of Cultural Affairs, as well as the Social Ministry of the Federal State of Mecklenburg-West Pomerania. The CMR encompasses several research projects that share data of the population-based Study of Health in Pomerania (SHIP; http://ship.community-medicine.de). This work is also part of the research project Greifswald Approach to Individualized Medicine (GANI_MED). The GANI_MED consortium is funded by the BMBF and the Ministry of Cultural Affairs of the Federal State of Mecklenburg-West Pomerania (03IS2061A). Instand e.V. provided partial grant support for the determination of plasma samples and data analysis. The KORA research platform and the KORA Augsburg studies are financed by the Helmholtz Zentrum München, German Research Center for Environmental Health $(\mathrm{GmbH})$, which is funded by the German Federal Ministry of Education, Science, Research and Technology and by the State of Bavaria. MR is supported by grants from the Else Kröner Fresenius Stiftung and the German Research Organization (Re 752/17-1).

\section{Author contribution statement}

A Hannemann, M Bidlingmaier, $\mathrm{H}$ Wallaschofski and M Reincke contributed equally to this work.

\section{Acknowledgements}

The contribution to data collection made by field workers, technicians, interviewers and computer assistants in both the studies is gratefully acknowledged.

\section{References}

1 Lewington S, Clarke R, Qizilbash N, Peto R \& Collins R. Age-specific relevance of usual blood pressure to vascular mortality: a metaanalysis of individual data for one million adults in 61 prospective studies. Lancet $20023 \mathbf{3 6 0}$ 1903-1913. (doi:10.1016/S01406736(02)11911-8)

2 Mancia G, Laurent S, Agabiti-Rosei E, Ambrosioni E, Burnier M, Caulfield MJ, Cifkova R, Clement D, Coca A, Dominiczak A, 
Erdine S, Fagard R, Farsang C, Grassi G, Haller H, Heagerty A, Kjeldsen SE, Kiowski W, Mallion JM, Manolis A, Narkiewicz K, Nilsson P, Olsen MH, Rahn KH, Redon J, Rodicio J, Ruilope L, Schmieder RE, Struijker-Boudier HA, Van Zwieten PA, Viigimaa M \& Zanchetti A. Reappraisal of European guidelines on hypertension management: a European Society of Hypertension Task Force document. Blood Pressure 200918 308-347. (doi:10.3109/ 08037050903450468 )

3 Miura K, Daviglus ML, Dyer AR, Liu K, Garside DB, Stamler J \& Greenland P. Relationship of blood pressure to 25-year mortality due to coronary heart disease, cardiovascular diseases, and all causes in young adult men: the Chicago Heart Association Detection Project in Industry. Archives of Internal Medicine 2001 161 1501-1508. (doi:10.1001/archinte.161.12.1501)

4 Funder JW, Carey RM, Fardella C, Gomez-Sanchez CE, Mantero F, Stowasser M, Young WF Jr \& Montori VM. Case detection, diagnosis, and treatment of patients with primary aldosteronism: an endocrine society clinical practice guideline. Journal of Clinical Endocrinology and Metabolism 200893 3266-3281. (doi:10. 1210/jc.2008-0104)

5 Milliez P, Girerd X, Plouin PF, Blacher J, Safar ME \& Mourad JJ. Evidence for an increased rate of cardiovascular events in patients with primary aldosteronism. Journal of the American College of Cardiology 200545 1243-1248. (doi:10.1016/j.jacc.2005.01. 015)

6 Quinkler M, Born-Frontsberg E \& Fourkiotis VG. Comorbidities in primary aldosteronism. Hormone and Metabolic Research 201042 429-434. (doi:10.1055/s-0029-1243257)

7 Young WF Jr. Minireview: primary aldosteronism - changing concepts in diagnosis and treatment. Endocrinology $2003 \mathbf{1 4 4}$ 2208-2213. (doi:10.1210/en.2003-0279)

8 Sealey JE, Gordon RD \& Mantero F. Plasma renin and aldosterone measurements in low renin hypertensive states. Trends in Endocrinology and Metabolism 200516 86-91. (doi:10.1016/j. tem.2005.02.006)

9 Mulatero P, Verhovez A, Morello F \& Veglio F. Diagnosis and treatment of low-renin hypertension. Clinical Endocrinology 2007 67 324-334. (doi:10.1111/j.1365-2265.2007.02898.x)

10 Jansen PM, Boomsma F \& van den Meiracker AH. Aldosteroneto-renin ratio as a screening test for primary aldosteronism - the Dutch ARRAT Study. Netherlands Journal of Medicine $2008 \mathbf{6 6}$ 220-228.

11 Fischer E, Beuschlein F, Bidlingmaier M \& Reincke M. Commentary on the Endocrine Society Practice Guidelines: consequences of adjustment of antihypertensive medication in screening of primary aldosteronism. Reviews in Endocrine $\mathcal{E}$ Metabolic Disorders 201112 43-48. (doi:10.1007/s11154-011-9163-7)

12 Seiler L, Rump LC, Schulte-Monting J, Slawik M, Borm K, Pavenstadt H, Beuschlein F \& Reincke M. Diagnosis of primary aldosteronism: value of different screening parameters and influence of antihypertensive medication. European Journal of Endocrinology 2004150 329-337. (doi:10.1530/eje.0.1500329)

13 Seifarth C, Trenkel S, Schobel H, Hahn EG \& Hensen J. Influence of antihypertensive medication on aldosterone and renin concentration in the differential diagnosis of essential hypertension and primary aldosteronism. Clinical Endocrinology 200257 457-465. (doi:10.1046/j.1365-2265.2002.01613.x)

14 Mulatero P, Rabbia F, Milan A, Paglieri C, Morello F, Chiandussi L \& Veglio F. Drug effects on aldosterone/plasma renin activity ratio in primary aldosteronism. Hypertension 200240 897-902. (doi:10. 1161/01.HYP.0000038478.59760.41)

15 Schwartz GL \& Turner ST. Screening for primary aldosteronism in essential hypertension: diagnostic accuracy of the ratio of plasma aldosterone concentration to plasma renin activity. Clinical Chemistry 200551 386-394. (doi:10.1373/clinchem.2004. 041780)

16 Williams JS, Williams GH, Raji A, Jeunemaitre X, Brown NJ, Hopkins PN \& Conlin PR. Prevalence of primary hyperaldosteronism in mild to moderate hypertension without hypokalaemia. Journal of Human Hypertension 200620 129-136. (doi:10.1038/ sj.jhh.1001948)
17 Westerdahl C, Bergenfelz A, Isaksson A, Wihl A, Nerbrand C \& Valdemarsson S. High frequency of primary hyperaldosteronism among hypertensive patients from a primary care area in Sweden. Scandinavian Journal of Primary Health Care 200624 154-159. (doi:10.1080/02813430600830931)

18 Mosso L, Carvajal C, Gonzalez A, Barraza A, Avila F, Montero J, Huete A, Gederlini A \& Fardella CE. Primary aldosteronism and hypertensive disease. Hypertension 200342 161-165. (doi:10. 1161/01.HYP.0000079505.25750.11)

19 Mulatero P, Stowasser M, Loh KC, Fardella CE, Gordon RD, Mosso L, Gomez-Sanchez CE, Veglio F \& Young WF Jr. Increased diagnosis of primary aldosteronism, including surgically correctable forms, in centers from five continents. Journal of Clinical Endocrinology and Metabolism 200489 1045-1050. (doi:10. 1210/jc.2003-031337)

20 Rossi GP, Bernini G, Caliumi C, Desideri G, Fabris B, Ferri C, Ganzaroli C, Giacchetti G, Letizia C, Maccario M, Mallamaci F, Mannelli M, Mattarello MJ, Moretti A, Palumbo G, Parenti G, Porteri E, Semplicini A, Rizzoni D, Rossi E, Boscaro M, Pessina AC \& Mantero F. A prospective study of the prevalence of primary aldosteronism in 1,125 hypertensive patients. Journal of the American College of Cardiology $2006 \mathbf{4 8}$ 2293-2300. (doi:10. 1016/j.jacc.2006.07.059)

21 Lim PO, Dow E, Brennan G, Jung RT \& MacDonald TM. High prevalence of primary aldosteronism in the Tayside hypertension clinic population. Journal of Human Hypertension $200014311-$ 315. (doi:10.1038/sj.jhh.1001013)

22 Gordon RD, Stowasser M, Tunny TJ, Klemm SA \& Rutherford JC. High incidence of primary aldosteronism in 199 patients referred with hypertension. Clinical and Experimental Pharmacology $\mathcal{E}$ Physiology 199421 315-318. (doi:10.1111/j.1440-1681. 1994.tb02519.x)

23 Volzke H, Alte D, Schmidt CO, Radke D, Lorbeer R, Friedrich N, Aumann N, Lau K, Piontek M, Born G, Havemann C, Ittermann T, Schipf S, Haring R, Baumeister SE, Wallaschofski H, Nauck M, Frick S, Arnold A, Junger M, Mayerle J, Kraft M, Lerch MM, Dorr M, Reffelmann T, Empen K, Felix SB, Obst A, Koch B, Glaser S, Ewert R, Fietze I, Penzel T, Doren M, Rathmann W, Haerting J, Hannemann M, Ropcke J, Schminke U, Jurgens C, Tost F, Rettig R, Kors JA, Ungerer S, Hegenscheid K, Kuhn JP, Kuhn J, Hosten N, Puls R, Henke J, Gloger O, Teumer A, Homuth G, Volker U, Schwahn C, Holtfreter B, Polzer I, Kohlmann T, Grabe HJ, Rosskopf D, Kroemer HK, Kocher T, Biffar R, John U \& Hoffmann W. Cohort profile: the Study of Health in Pomerania. International Journal of Epidemiology 201140 294-307. (doi:10. 1093/ije/dyp394)

24 Holle R, Happich M, Lowel H \& Wichmann HE. KORA - a research platform for population based health research. Gesundheitswesen 200567 (Suppl 1) S19-S25. (doi:10.1055/s-2005-858235)

25 Meisinger C, Heier M, Volzke H, Lowel H, Mitusch R, Hense HW \& Ludemann J. Regional disparities of hypertension prevalence and management within Germany. Journal of Hypertension 200624 293-299. (doi:10.1097/01.hjh.0000200508.10324.8e)

26 Calhoun DA, Jones D, Textor S, Goff DC, Murphy TP, Toto RD, White A, Cushman WC, White W, Sica D, Ferdinand K, Giles TD, Falkner B \& Carey RM. Resistant hypertension: diagnosis, evaluation, and treatment. A scientific statement from the American Heart Association Professional Education Committee of the Council for High Blood Pressure Research. Hypertension 200851 1403-1419. (doi:10.1161/HYPERTENSIONAHA.108.189141)

27 Mancia G, De Backer G, Dominiczak A, Cifkova R, Fagard R, Germano G, Grassi G, Heagerty AM, Kjeldsen SE, Laurent S, Narkiewicz K, Ruilope L, Rynkiewicz A, Schmieder RE, Boudier HA, Zanchetti A, Vahanian A, Camm J, De Caterina R, Dean V, Dickstein K, Filippatos G, Funck-Brentano C, Hellemans I, Kristensen SD, McGregor K, Sechtem U, Silber S, Tendera M, Widimsky P, Zamorano JL, Erdine S, Kiowski W, Agabiti-Rosei E, Ambrosioni E, Lindholm LH, Viigimaa M, Adamopoulos S, Bertomeu V, Clement D, Farsang C, Gaita D, Lip G, Mallion JM, Manolis AJ, Nilsson PM, O'Brien E, Ponikowski P, Redon J, Ruschitzka F, Tamargo J, van Zwieten P, Waeber B \& Williams B. 
Guidelines for the management of arterial hypertension: the Task Force for the Management of Arterial Hypertension of the European Society of Hypertension (ESH) and of the European Society of Cardiology (ESC). Journal of Hypertension 200725 1105-1187. (doi:10.1097/HJH.0b013e3281fc975a)

28 Hannemann A, Friedrich N, Ludemann J, Volzke H, Rettig R, Peters J. Reincke M, Doring A, Nauck M \& Wallaschofski H. Reference intervals for aldosterone, renin, and the aldosteroneto-renin ratio in the population-based Study of Health in Pomerania (SHIP-1). Hormone and Metabolic Research 201042 392-399. (doi:10.1055/s-0030-1247545)

29 Kidambi S, Kotchen JM, Grim CE, Raff H, Mao J, Singh RJ \& Kotchen TA. Association of adrenal steroids with hypertension and the metabolic syndrome in blacks. Hypertension $2007 \mathbf{4 9}$ 704-711. (doi:10.1161/01.HYP.0000253258.36141.c7)

30 Garg R, Hurwitz S, Williams GH, Hopkins PN \& Adler GK. Aldosterone production and insulin resistance in healthy adults. Journal of Clinical Endocrinology and Metabolism 201095 19861990. (doi:10.1210/jc.2009-2521)

31 Grim CE, Cowley AW Jr, Hamet P, Gaudet D, Kaldunski ML, Kotchen JM, Krishnaswami S, Pausova Z, Roman R, Tremblay J \& Kotchen TA. Hyperaldosteronism and hypertension: ethnic differences. Hypertension 200545 766-772. (doi:10.1161/01. HYP.0000154364.00763.d5)

32 Manolopoulou J, Bielohuby M, Caton SJ, Gomez-Sanchez CE, Renner-Mueller I, Wolf E, Lichtenauer UD, Beuschlein $\mathrm{F}$, Hoeflich A \& Bidlingmaier M. A highly sensitive immunofluorometric assay for the measurement of aldosterone in small sample volumes: validation in mouse serum. Journal of Endocrinology 2008196 215-224. (doi:10.1677/JOE-07-0134)

33 Morganti A. A comparative study on inter and intralaboratory reproducibility of renin measurement with a conventional enzymatic method and a new chemiluminescent assay of immunoreactive renin. Journal of Hypertension 201028 1307-1312. (doi:10.1097/ 01.hjh.0000379399.50039.3c)

34 Rossi GP, Barisa M, Belfiore A, Desideri G, Ferri C, Letizia C, Maccario M, Morganti A, Palumbo G, Patalano A, Roman E, Seccia TM, Pessina AC \& Mantero F. The aldosterone-renin ratio based on the plasma renin activity and the direct renin assay for diagnosing aldosterone-producing adenoma. Journal of Hypertension 201028 1892-1899. (doi:10.1097/HJH.0b013e 32833d2192)
35 Young WF. Primary aldosteronism: renaissance of a syndrome. Clinical Endocrinology 200766 607-618. (doi:10.1111/j.13652265.2007.02775.x)

36 Rossi GP, Pessina AC \& Heagerty AM. Primary aldosteronism: an update on screening, diagnosis and treatment. Journal of Hypertension 200826 613-621. (doi:10.1097/HJH.0b013e3282f4b3e6)

37 Satoh F, Morimoto R, Iwakura Y, Ono Y, Kudo M, Takase K \& Ito S. Primary aldosteronism: a Japanese perspective. Reviews in Endocrine \& Metabolic Disorders 201112 11-14. (doi:10.1007/ s11154-011-9161-9)

38 Calhoun DA. Is there an unrecognized epidemic of primary aldosteronism? Hypertension $2007 \mathbf{5 0} 447-453$. (doi:10.1161/ HYPERTENSIONAHA.106.086116)

39 Kaplan NM. Is there an unrecognized epidemic of primary aldosteronism? Hypertension 200750 454-458. (doi:10.1161/ HYPERTENSIONAHA.106.086124)

40 Calhoun DA, Nishizaka MK, Zaman MA, Thakkar RB \& Weissmann P. Hyperaldosteronism among black and white subjects with resistant hypertension. Hypertension $2002 \mathbf{4 0}$ 892-896. (doi:10.1161/01.HYP.0000040261.30455.B6)

41 Olivieri O, Ciacciarelli A, Signorelli D, Pizzolo F, Guarini P, Pavan C, Corgnati A, Falcone S, Corrocher R, Micchi A, Cressoni C \& Blengio G. Aldosterone to renin ratio in a primary care setting: the Bussolengo study. Journal of Clinical Endocrinology and Metabolism 200489 4221-4226. (doi:10.1210/jc.2003-032179)

42 Newton-Cheh C, Guo CY, Gona P, Larson MG, Benjamin EJ, Wang TJ, Kathiresan S, O'Donnell CJ, Musone SL, Camargo AL, Drake JA, Levy D, Hirschhorn JN \& Vasan RS. Clinical and genetic correlates of aldosterone-to-renin ratio and relations to blood pressure in a community sample. Hypertension $2007 \mathbf{4 9}$ 846-856. (doi:10.1161/01.HYP.0000258554.87444.91)

43 Stowasser M \& Gordon RD. Primary aldosteronism. Best Practice \& Research. Clinical Endocrinology \& Metabolism 200317 591-605. (doi:10.1016/S1521-690X(03)00050-2)

Received 21 November 2011

Revised version received 9 March 2012

Accepted 10 April 2012 